\title{
LONGITUDINAL SYSTOLIC DYSFUNCTION IN HYPERTENSIVE CARDIOMYOPATHY WITH NORMAL EJECTION FRACTION
}

\author{
Jose Salas ${ }^{1}$, Oscar Sanchez ${ }^{2}$, Oscar Baltazar González ${ }^{3}$, and Maria Elena Soto ${ }^{4}$ \\ ${ }^{1}$ Centenario Hospital Miguel Hidalgo \\ ${ }^{2}$ Antiguo Hospital Civil de Guadalajara Fray Antonio Alcalde \\ ${ }^{3}$ Hospital Civil de Guadalajara Unidad Hospitalaria Juan I Menchaca \\ ${ }^{4}$ INC IGNACIO CHAVEZ
}

September 24, 2021

\begin{abstract}
Background: The left ventricle (LV) journey in their transition from hypertrophy to heart failure is marked by many subcellular events partially understood yet. The moment in which the structural abnormalities reach the umbral to induce myocardial dysfunction remains elusive. Aims: To evaluate the anatomic-functional relationship between LV wall thickness and longitudinal systolic dysfunction. Material and Methods: We prospectively performed clinical history and transthoracic echocardiogram on healthy individuals and patients with hypertension, left ventricle ejection fraction (LVEF) [?]50\%, and absence of heart failure symptoms. Results: A total of 226 patients and 101 healthy individuals were recruited. The distribution for sex was similar between groups. The mean age was $67 \pm 13$ years old in the patients, and $44 \%$ had concentric LV hypertrophy. LVEF was identical in both groups (63 $\pm 6 \%$ ); in contrast, global longitudinal strain (GLS) (-18.8 $\pm 2.5 \%$ vs. $-20.4 \pm 2 \%$ ) and mitral annulus plane systolic excursion (MAPSE) (13.8 \pm 2.8 vs. $15.5 \pm 2 \mathrm{~mm}$ ) were lower. ROC curve classified optimally decreased GLS with LV septum thickness [?]13mm and decreased MAPSE with thickness [?]14mm. Multivariable logistic regression found that LV septum thickness is the only variable associated with longitudinal systolic dysfunction $(\mathrm{OR}=1.1, \mathrm{CI} 95 \%=1.05-1.15, \mathrm{p}=0.001$, $\mathrm{R}$ squared=0.38). Discussion: A progressive increase in LV wall thickness due to myocyte hypertrophy and interstitial expansion is associated with LV systolic longitudinal dysfunction. Conclusions: Patients with moderate or severe ventricular hypertrophy (septum [?]13mm) had longitudinal systolic dysfunction, GLS decreases with minor structural change than MAPSE, and LVEF is insensitive in detecting longitudinal myocardial dysfunction in patients with hypertension.
\end{abstract}

\section{LONGITUDINAL SYSTOLIC DYSFUNCTION IN HYPERTENSIVE CARDIOMYOPA- THY WITH NORMAL EJECTION FRACTION}

\section{Shortened title: LONGITUDINAL SYSTOLIC DYSFUNCTION IN HYPERTENSIVE CARDIOMY- OPATHY}

Salas-Pacheco José L. MD, MSc

José Luis Salas Pacheco

Cardiology department, Centenario Hospital Miguel Hidalgo

Ferrocarril avenue, Alameda. Aguascalientes México. Zip code: 20259

Lomelí-Sánchez Oscar MD, MSc 
Oscar Lomelí Sánchez

Cardiology department, Antiguo Hospital Civil de Guadalajara Fray Antonio Alcalde

Coronel Calderón 777, El Retiro, Guadalajara, México. Zip code: 44280

Baltazar-González O. MD

Oscar Baltazar González

Cardiology department, Hospital Civil Juan I. Menchaca

Salvador Quevedo, Independencia, Guadalajara, México. Zip code: 44340

Soto ME MD, MSc, PhD

María Elena Soto López

Immunology department, Instituto Nacional de Cardiología Ignacio Chávez

Juan Badiano 1, Sección XVI, Tlalpan, México City, Zip code: 14080

\section{Corresponding author:}

Salas-Pacheco José L. MD, MSc

José Luis Salas Pacheco

Cardiology department, Centenario Hospital Miguel Hidalgo

Ferrocarril avenue, Alameda. Aguascalientes México. Zip code: 20259

mail: jolsalp@gmail.com

telephone: 4499946720

fax: none

\section{ABSTRACT}

Background: The left ventricle (LV) journey in their transition from hypertrophy to heart failure is marked by many subcellular events partially understood yet. The moment in which the structural abnormalities reach the umbral to induce myocardial dysfunction remains elusive.

Aims: To evaluate the anatomic-functional relationship between LV wall thickness and longitudinal systolic dysfunction.

Material and Methods: We prospectively performed clinical history and transthoracic echocardiogram on healthy individuals and patients with hypertension, left ventricle ejection fraction (LVEF) [?] $50 \%$, and absence of heart failure symptoms.

Results: A total of 226 patients and 101 healthy individuals were recruited. The distribution for sex was similar between groups. The mean age was $67+-13$ years old in the patients, and $44 \%$ had concentric LV hypertrophy. LVEF was identical in both groups (63+-6\%); in contrast, global longitudinal strain (GLS) (-18.8+-2.5\% vs. $-20.4+-2 \%)$ and mitral annulus plane systolic excursion (MAPSE) (13.8+-2.8 vs. 15.5+$2 \mathrm{~mm}$ ) were lower. ROC curve classified optimally decreased GLS with LV septum thickness [?]13mm and decreased MAPSE with thickness [?]14mm. Multivariable logistic regression found that LV septum thickness is the only variable associated with longitudinal systolic dysfunction $\left(\mathrm{OR}=1.1, \mathrm{CI}_{95 \%}=1.05-1.15, \mathrm{p}=0.001\right.$, $\mathrm{R}$ squared $=0.38$ ).

Discussion: A progressive increase in LV wall thickness due to myocyte hypertrophy and interstitial expansion is associated with LV systolic longitudinal dysfunction. 
Conclusions: Patients with moderate or severe ventricular hypertrophy (septum [?]13mm) had longitudinal systolic dysfunction, GLS decreases with minor structural change than MAPSE, and LVEF is insensitive in detecting longitudinal myocardial dysfunction in patients with hypertension.

Keywords

Hypertension, Left ventricular hypertrophy, Left ventricular dysfunction, Heart failure

\section{LONGITUDINAL SYSTOLIC DYSFUNCTION IN HYPERTENSIVE CARDIOMYOPA- THY WITH NORMAL EJECTION FRACTION}

\section{INTRODUCTION}

Myocardial alterations originated from hypertension are collectively known as hypertensive heart disease. Structurally it is characterized by increased left ventricle (LV) wall thickness, concentric LV hypertrophy, and left atrium dilatation. There are abnormalities predominantly in diastolic function in the early stages, while in the late, arise ventricular dilatation, systolic dysfunction, and decreased ejection fraction ${ }^{1}$. Despite preserved left ventricular ejection fraction (LVEF), some patients have abnormalities in the longitudinal components of contractile mechanics and systolic dysfunction in the early stages ${ }^{2}$. Previous evidence proposed increased circumferential and radial functions as the compensatory mechanisms that maintained LVEF in the normal range $^{3}$. However, increased LV wall thickness due to hypertrophy and myocardial incompressibility are the factors that create the artifact that results in normal $\mathrm{LVEF}^{4}$. Thus, in patients with hypertensive heart disease, systolic dysfunction can be observed since early stages, before symptoms of heart failure or decrease in global systolic function indices appear ${ }^{5}$. Multiple structural and functional events characterize the continuum from LV hypertrophy to heart failure; however, the point in which occurs the transition to ventricular dysfunction remains elusive. This study aimed to evaluate the anatomic-functional relationship between LV wall thickness and longitudinal systolic dysfunction in individuals with hypertension, normal LVEF, and absence of heart failure symptoms.

\section{METHODS}

We prospectively recruited from our hypertension clinics between June 2020 to March 2021 patients 18 years and older, of both sexes, with a diagnosis of hypertension defined as systolic blood pressure greater than $140 \mathrm{mmHg}$ or diastolic greater than $90 \mathrm{mmHg}$ or under antihypertensive treatment. We excluded patients with LVEF less than 50\%, moderate or severe mitral annulus calcification, moderate or severe valvular disease, presence of a pacemaker or defibrillator, advanced chronic kidney disease, and a history of cardiac surgery or ischemic heart disease. In addition, healthy individuals 18 years older were included and matched for age and sex with the patients.

A detailed clinical history, physical examination, and echocardiogram were performed on both groups. The transthoracic echocardiogram was made with a contemporary ultrasound machine (Epiq 7, Philips, Andover MA) and a sectorial transducer $(2-5 \mathrm{MHz})$ following the American Society of Echocardiography (ASE) recommendations ${ }^{6}$. Images and video clips acquired in B-mode were used to quantify the diameters and volume of the different cavities. LV mass was calculated using the modified Devereux formula ${ }^{7}$. The left atrium and LV volumes were calculated using the Simpson method. LV geometry was obtained based on LV mass index (MI) and relative wall thickness (RWT). Normal geometry was defined as RWT $<0.43$ and LVMI $<95 \mathrm{~g} / \mathrm{m}^{2}$ in women or $<115 \mathrm{~g} / \mathrm{m}^{2}$ in men. Concentric remodeling as RWT [?] 0.43 and LVMI $<$ $95 \mathrm{~g} / \mathrm{m}^{2}$ in women or $<115 \mathrm{~g} / \mathrm{m}^{2}$ in men. And concentric hypertrophy as RWT [?] 0.43 and LVMI [?] 95 $\mathrm{g} / \mathrm{m}^{2}$ in women or [?] $115 \mathrm{~g} / \mathrm{m}^{2}$ in $\operatorname{men}^{6}$.

LVEF was obtained with the biplanar method in apical four and two-chamber views. Mitral annulus plane systolic excursion (MAPSE) was quantified as the average of the values obtained from the displacement of the medial and lateral mitral annulus towards the apex during systole, measured in apical four-chamber view with $\mathrm{M}$ mode. Left ventricular diastolic function was evaluated according to the ASE recommendations, using transmitral flow pulsed Doppler, mitral annulus tissue Doppler velocities, left atrium volume, and the tricuspid regurgitation jet maximum velocity ${ }^{8}$. The pulmonary artery systolic pressure was obtained by 
adding to this last value the right atrium pressure (estimated by the diameter and collapsibility of the inferior vena cava).

B-mode images were acquired for deformation analysis between 40 and $80 \mathrm{~Hz}$ in apical four-chamber, twochamber, and long-axis projections. They were processed offline with QLab Software, version 13 (Philips, Andover MA). Once adequate tracking of the region of interest was corroborated by visual inspection, the images were approved for analysis. Global LV longitudinal strain (GLS) was calculated as the average value of longitudinal deformation of $17 \mathrm{LV}$ segments.

We defined LV longitudinal dysfunction as GLS greater than -17\% or decreased MAPSE. Limits for MAPSE were established based on sex and age ${ }^{9}$. In women younger than 60 years, low MAPSE was [?]10mm, in those older than 60 years [?]8mm. In men younger than 60 years, [?]11 $\mathrm{mm}$ and more aged than 60 years [?] $9 \mathrm{~mm}$. The Institutional ethics committee approved the study, and each patient consented to participate in the study.

\section{STATISTICAL ANALYSIS}

According to their distribution, the variables are described with mean +- standard deviation or median with interquartile range 25-75. The Kolmogorov-Smirnov test evaluated the distribution normality. The comparisons between clinical and echocardiographic variables were performed with the Chi-square test, student t-test, or Mann Whitney U-test according to variable type and distribution. Correlations were assessed with Pearson's or Spearman's correlation coefficients. Differences between subgroups of patients with hypertension (subdivided according to LV geometry) were calculated with one-way ANOVA with Tukey's posthoc test. Multivariate analysis was performed with binomial logistic regression, considering longitudinal systolic dysfunction as the dependent variable. The receiver operating characteristic (ROC) curve identified the optimal Youden point for classifying longitudinal systolic dysfunction based on LV septum diameter. Differences were considered significant when the p-value was less than 0.05 bilaterally. The analysis was performed with $\mathrm{R}$ software, version 4.03, interface with $\mathrm{R}$ studio.

\section{RESULTS}

A total of 226 patients with hypertension and 101 healthy individuals were included. The group with hypertension was older, more obese, and blood pressure was higher. The mean duration of hypertension was $4.3+-1.6$ years. The distribution for sex was similar between groups. Table 1 shows demographic characteristics.

In all healthy individuals, the echocardiogram was normal. LVEF was $63+-6 \%$. MAPSE was $15.5+-2$ $\mathrm{mm}$ and correlated inversely with age. Lateral mitral tissue Doppler S' wave velocity was $10+-2.2 \mathrm{~cm} / \mathrm{sec}$ and GLS -20.4+-2\%. LV diastolic function was normal in 57 (56.4\%); the remainder showed slow relaxation. Those with normal diastolic function were younger (47+-12 vs. $65.8+-13$ years, $\mathrm{p}=0.001)$; however, $\mathrm{E} / \mathrm{e}$ ' ratio was normal in all and without difference according to age $(6.4+-1.9$ vs. $6.7+-2.2, \mathrm{p}=0.09)$.

The patients had multiple structural and functional cardiac abnormalities. Table 2 shows echocardiographic data. Only $28(13 \%)$ patients had normal LV geometry; the rest, concentric remodeling or concentric hypertrophy. LVEF was similar to that of the control group. In contrast, GLS was lower (-18.8+-2.5\% vs $-20.4+-2 \%$ ), as were S' mitral velocity ( $8+-2.2$ vs $10+-2.2 \mathrm{~cm} / \mathrm{sec})$ and MAPSE (13.8+-2.8 vs $15.5+-2 \mathrm{~mm})$. We found decreased GLS in $27 \%$ of patients and decreased MAPSE in 12\%. Most patients had grade 1 diastolic dysfunction, and only $14 \%$ had grade 2 diastolic dysfunction. None showed a restrictive filling pattern.

Table 3 shows the characteristics of the patients when analyzed according to the type of ventricular geometry. The geometric pattern predominantly associated with longitudinal dysfunction was concentric hypertrophy. GLS was abnormal in 62 patients, of whom $50(80 \%)$ had concentric hypertrophy. Similarly, of 27 patients with low MAPSE, 26 (96\%) had concentric hypertrophy. A progressive increase in LV septum thickness was related to the deterioration of longitudinal systolic function (Figure 1). 
In patients of both sexes with low GLS, we observed that the mean septal thickness was $13.4 \mathrm{~mm}$, while low MAPSE occurred with $13.8 \mathrm{~mm}$ in women and $14.1 \mathrm{~mm}$ in men. All patients with low MAPSE had concomitantly low GLS.

By ROC curve (Figures 2 and 3) it was recognized that LV septum diameter greater than 13mm classifies adequately patients with low GLS (AUC $=0.85$, sensitivity $71 \%$, specificity $82 \%, \mathrm{p}=0.001$ ), and septal diameter of $14 \mathrm{~mm}$ low MAPSE (AUC $=0.9$, sensitivity $74 \%$, specificity $90 \%, \mathrm{p}=0.001$ ).

In contrast to patients with normal longitudinal function, those with dysfunction had severe left atrium dilatation, worse diastolic function, and higher pulmonary artery systolic pressure. Despite the plethora of structural and functional disturbances, LVEF was similar among the different geometric patterns, and did not show correlation with LV septum thickness $(\mathrm{r}=0.04, \mathrm{p}=0.5)$, GLS $(\mathrm{r}=-0.2, \mathrm{p}=0.01)$ or MAPSE $(\mathrm{r}=$ $0.13, \mathrm{p}=0.05)$. On the other hand, MAPSE and GLS showed hight correlation $(\mathrm{r}=-0.7, \mathrm{p}=0.001)$.

LV longitudinal systolic dysfunction was related to body weight, greater ventricular wall thickness, worst ventricular geometry, and greater LV mass in the hypertensive group. However, in multivariate analysis, only LV septum thickness was independently associated. Each millimeter of increase in LV septum diameter increased the Odds Ratio of longitudinal dysfunction by $10\left(\mathrm{OR}=1.1, \mathrm{CI}_{95 \%}=1.05-1.15, \mathrm{p}=0.001, \mathrm{R}\right.$ squared $=0.38)$. High collinearity was observed between ventricular wall thickness with ventricular geometry and mass, an expected result since the latter two variables derive from the former.

\section{DISCUSSION}

The main findings of this study showed that only patients with moderate or severe ventricular hypertrophy (septum [?]13mm) had longitudinal systolic dysfunction, that GLS decrease with minor structural change than MAPSE, and that LVEF is insensitive in detecting longitudinal myocardial dysfunction in patients with hypertension.

In the different geometric patterns, LVEF was similar. However, longitudinal systolic function worsened as LV septum thickness increased. MacIver et al. described this finding using a mathematical model; it corrected LVEF based on wall thickness and myocardial strain ${ }^{10}$. The MacIver hypothesis was confirmed in patients with hypertensive heart disease with concentric LV hypertrophy and patients with heart failure with preserved LVEF ${ }^{11-14}$. Similarly, Shimizu et al. observed in individuals with hypertensive cardiomyopathy a subnormal systolic function (lower midmyocardium fractional shortening) despite preserved ejection fraction (normal endocardial fractional shortening) ${ }^{15}$. Therefore, LV geometric modifications and the principle of myocardial incompressibility account for normal LVEF in hearts whit longitudinal dysfunction. Myocardial incompressibility states that myocardial shortening in longitudinal direction causes thickening in the orthogonal plane; thus, myocardial volume remains relatively constant throughout the cardiac cycle ${ }^{16}$. The only variation in myocardial volume was described by Yin et al., as approximately $2-4 \mathrm{ml}$ per $100 \mathrm{~g}$ of tissue and is the result of compression of intramyocardial blood vessels ${ }^{17}$.

Based on wall thickness, left ventricular hypertrophy is classified arbitrarily as mild (10-12mm in women or $11-13 \mathrm{~mm}$ in men), moderate $(13-15 \mathrm{~mm}$ in women or $14-16 \mathrm{~mm}$ in men), or severe $(>15 \mathrm{~mm}$ in women or $>16 \mathrm{~mm})^{18}$. The Increased myocyte diameter and expansion of the interstitium due to pathological fibrosis cause ventricular wall thickening ${ }^{19}$. The increase in connective tissue initially impairs diastolic function and then the systolic. In this work, we observed that only patients with moderate or severe hypertrophy presented longitudinal dysfunction. Previous histological studies showed a direct relationship between LV pressure overload and myocardial fibrous tissue content. In his seminal study, Rossi observed in postmortem hearts that the normal connective tissue matrix volume is $6.7 \%$; however, there was connective tissue volume expansion up to $31 \%$ in patients with hypertension ${ }^{20}$. The fibrotic process affects the entire ventricular wall diffusely. However, the subendocardium suffers earlier dysfunction due to its distal location from epicardial coronary flow, extreme changes in pressure and compression, and intrinsic susceptibility to microvascular fibrosis ${ }^{21}$. Increased damage to the subendocardium results in longitudinal LV dysfunction that is echocardiographically evident only as diastolic dysfunction, despite normal LVEF. The use of more sensitive techniques than LVEF may reveal LV longitudinal systolic dysfunction. 
Hypertension and ventricular hypertrophy are risk factors for heart failure. It was observed that at least twothirds of patients with heart failure with preserved LVEF have systolic dysfunction (decreased GLS) ${ }^{22}$. In this study, although we included only patients without heart failure, longitudinal systolic dysfunction was present in $27.4 \%$ measured by GLS and $11.9 \%$ by MAPSE. This finding suggests that functional alterations are present long before the onset of heart failure. As demonstrated in multiple studies, LV strain quantification by speckle tracking is a more sensitive technique in the earlier detection of functional abnormalities ${ }^{23}$. On the other hand, MAPSE is easy to quantify, highly reproducible, and does not require adequate sonographic windows nor advanced echocardiographic modalities.

According to the results of this study, LVEF does not provide specific information on the myocardium's contractile mechanics or contractile state in hypertensive patients. Given that hypertension and ventricular hypertrophy are precursors of heart failure, we should reconsider how we quantify ventricular function in this population. If moderate or severe LV wall thickness or systolic dysfunction are identified, patients could benefit from the appropriate therapeutic intervention for preventing the evolution to heart failure.

\section{CONCLUSIONS}

The results of this work allow us to make the anatomical-functional association between increased LV wall thickness and longitudinal systolic dysfunction in patients with hypertension. Only moderate or severe LV septal thickening $(>13 \mathrm{~mm})$ has an association with longitudinal dysfunction. LV abnormal geometry and myocardial incompressibility are the mechanisms that create the artifact of normal LVEF in the presence of systolic dysfunction. Quantification of MAPSE and GLS overcomes LVEF limitations and provides essential information on the myocardial contractile state in hypertensive patients without heart failure symptoms.

Bibliography

1. Drazner MH. The Progression of Hypertensive Heart Disease. Circulation. 2011; 123:327-334.

2. Diamond JA, Phillips RA. Hypertensive heart disease. Hypertens Res. 2005 Mar;28(3):191-202.

3. Mizuguchi Y, Oishi Y, Miyoshi H, Iuchi A, Nagase N, Oki T. The functional role of longitudinal, circumferential, and radial myocardial deformation for regulating the early impairment of left ventricular contraction and relaxation in patients with cardiovascular risk factors: a study with two-dimensional strain imaging. J Am Soc Echocardiogr. 2008 Oct;21(10):1138-44.

4. Aurigemma GP, Silver KH, Priest MA, Gaasch WH. Geometric changes allow normal ejection fraction despite depressed myocardial shortening in hypertensive left ventricular hypertrophy. J Am Coll Cardiol $1995 ; 26: 195-202$.

5. Ballo P, Quatrini I, Giacomin E, Motto A, Mondillo S. Circumferential versus longitudinal systolic function in patients with hypertension: a nonlinear relation. J Am Soc Echocardiogr. 2007 Mar;20(3):298-306.

6. Lang RM, Badano LP, Mor-Avi V, Afilalo J, Armstrong A, Ernande L, Flachskampf FA, Foster E, Goldstein SA, Kuznetsova T, Lancellotti P, Muraru D, Picard MH, Rietzschel ER, Rudski L, Spencer KT, Tsang W, Voigt JU. Recommendations for cardiac chamber quantification by echocardiography in adults: an update from the American Society of Echocardiography and the European Association of Cardiovascular Imaging. J Am Soc Echocardiogr. 2015 Jan;28(1):1-39.e14.

7. Devereux RB, Reichek N. Echocardiographic determination of left ventricular mass in man. Anatomic validation of the method. Circulation. 1977 Apr;55(4):613-8.

8. Nagueh SF, Smiseth OA, Appleton CP, Byrd BF 3rd, Dokainish H, Edvardsen T, Flachskampf FA, Gillebert TC, Klein AL, Lancellotti P, Marino P, Oh JK, Popescu BA, Waggoner AD. Recommendations for the Evaluation of Left Ventricular Diastolic Function by Echocardiography: An Update from the American Society of Echocardiography and the European Association of Cardiovascular Imaging. J Am Soc Echocardiogr. 2016 Apr;29(4):277-314. 
9. Stoylen, A, Molmen, HE, Dalen, H. Relation between Mitral Annular Plane Systolic Excursion and Global longitudinal strain in normal subjects: The HUNT study. Echocardiography. 2018; 35: 603-610.

10. David H. MacIver, A new method for quantification of left ventricular systolic function using a corrected ejection fraction, European Journal of Echocardiography, Volume 12, Issue 3, March 2011, Pages 228-234.

11. Vinereanu D, Nicolaides E, Tweddel AC, Fraser AG. "Pure" diastolic dysfunction is associated with long-axis systolic dysfunction. Implications for the diagnosis and classification of heart failure. Eur J Heart Fail. 2005 Aug;7(5):820-8

12. Szelenyi Z, Fazakas A, Szenasi G, Tegze N, Fekete B, Molvarec A, Hadusfalvy-Sudar S, Janosi O, Kiss M, Karadi I, Vereckei A. The mechanism of reduced longitudinal left ventricular systolic function in hypertensive patients with normal ejection fraction. J Hypertens. 2015 Sep;33(9):1962-9; discussion 1969).

13. Tan YT, Wenzelburger F, Lee E, et al. The pathophysiology of heart failure with normal ejection fraction: exercise echocardiography reveals complex abnormalities of both systolic and diastolic ventricular function involving torsion, untwist, and longitudinal motion. J Am Coll Cardiol. 2009; 54:36-46

14. Mizuguchi Y, Oishi Y, Miyoshi H, Iuchi A, Nagase N, Oki T. Concentric left ventricular hypertrophy brings deterioration of systolic longitudinal, circumferential and radial myocardial deformation in hypertensive patients with preserved left ventricular pump function. J Cardiol 2010; 55:23-33.

15. Shimizu G, Hirota Y, Kita Y, Kawamura K, Saito T, Gaasch WH. Left ventricular midwall mechanics in systemic arterial hypertension. Myocardial function is depressed in pressure-overload hypertrophy. Circulation. 1991 May;83(5):1676-84.

16. Yin FC, Chan CC, Judd RM. Compressibility of perfused passive myocardium. Am J Physiol. 1996; Nov;271(5 Pt 2): H1864-70.

17. Tsuiki K, Ritman EL. Direct evidence that left ventricular myocardium is incompressible throughout systole and diastole. Tohoku J Exp Med. 1980 Sep;132(1):119-20.

18. Lang RM, Bierig M, Devereux RB, Flachskampf FA, Foster E, Pellikka PA, et al. Recommendations for chamber quantification: a report from the American Society of Echocardiography's Guidelines and Standards Committee and the Chamber Quantification Writing Group, developed in conjunction with the European Association of Echocardiography, a branch of the European Society of Cardiology. J Am Soc Echocardiogr. 2005, vol. 18 (pg. 1440-63).

19. Diez J. Mechanisms of cardiac fibrosis in hypertension. J Clin Hypertens (Greenwich). 2007 Jul;9(7):54650.

20. Rossi MA. Pathologic fibrosis and connective tissue matrix in left ventricular hypertrophy due to chronic arterial hypertension in humans. Journal of Hypertension 1998, 16:1031-1041.

21. Schwartzkopff B, Motz W, Frenzel H, Vogt M, Knauer S, Strauer BE. Structural and functional alterations of the intramyocardial coronary arterioles in patients with arterial hypertension. Circulation 1993; 88:993-1003).

22. Kraigher-Krainer E, Shah AM, Gupta DK, Santos A, Claggett B, Pieske B, Zile MR, Voors AA, Lefkowitz MP, Packer M, McMurray JJ, Solomon SD; PARAMOUNT Investigators. Impaired systolic function by strain imaging in heart failure with preserved ejection fraction. J Am Coll Cardiol. 2014 Feb 11;63(5):447-56.

23. Zito C, Longobardo L, Citro R, Galderisi M, Oreto L, Carerj ML, Manganaro R, Cusma-Piccione M, Todaro MC, Di Bella G, Imbalzano E, Khandheria BK, Carerj S. Ten Years of 2D Longitudinal Strain for Early Myocardial Dysfunction Detection: A Clinical Overview. Biomed Res Int. 2018 Dec 5;2018: 8979407.

Table 1. Demographic characteristics 


\begin{tabular}{|c|c|c|c|c|}
\hline Variable & Global $\mathrm{n}=327$ & $\begin{array}{l}\text { Hypertension } n= \\
226\end{array}$ & Control $n=101$ & $\mathbf{p}$ \\
\hline Age & $60(17.8)$ & $67(13)$ & $55(15)$ & 0.001 \\
\hline $\begin{array}{l}\text { Gender female } \\
\text { male }\end{array}$ & $214(60) 141(40)$ & $143(63) 83(37)$ & $71(70) 30(30)$ & 0.13 \\
\hline Weight & $74.4(16)$ & $76(17)$ & $71(13)$ & 0.008 \\
\hline Height & $163(9.7)$ & $161(9.9)$ & $165(8.3)$ & 0.004 \\
\hline BMI & $28(5)$ & $29(5.4)$ & $26(4.2)$ & 0.001 \\
\hline BSA & $1.8(0.22)$ & $1.84(2.4)$ & $1.8(0.19)$ & 0.9 \\
\hline Obesity & $104(29)$ & $82(36)$ & $22(21)$ & 0.006 \\
\hline Overweight & $153(43)$ & $98(43)$ & $55(54)$ & 0.04 \\
\hline $\begin{array}{l}\text { Arterial } \\
\text { pressure Systolic }\end{array}$ & $\begin{array}{l}126(15) 78(9) 94 \\
(10) 48(11)\end{array}$ & $\begin{array}{l}134(11.3) 81(8) \\
99(8) 52(10)\end{array}$ & $\begin{array}{l}111(8.4) 71(5.7) \\
85(5.7) 40(7.6)\end{array}$ & $\begin{array}{lll}0.001 & 0.001 & 0.001 \\
0.001 & \end{array}$ \\
\hline $\begin{array}{l}\text { Diastolic Mean } \\
\text { AP Pulse pressure }\end{array}$ & & & & \\
\hline Diabetes & $28(7)$ & $28(12.3)$ & 0 & \\
\hline $\begin{array}{l}\text { AP: arterial } \\
\text { pressure, BMI: } \\
\text { body mass index, } \\
\text { BSA: body } \\
\text { surface area. }\end{array}$ & $\begin{array}{l}\text { AP: arterial } \\
\text { pressure, BMI: } \\
\text { body mass index, } \\
\text { BSA: body } \\
\text { surface area. }\end{array}$ & $\begin{array}{l}\text { AP: arterial } \\
\text { pressure, BMI: } \\
\text { body mass index, } \\
\text { BSA: body } \\
\text { surface area. }\end{array}$ & $\begin{array}{l}\text { AP: arterial } \\
\text { pressure, BMI: } \\
\text { body mass index, } \\
\text { BSA: body } \\
\text { surface area. }\end{array}$ & $\begin{array}{l}\text { AP: arterial } \\
\text { pressure, BMI: } \\
\text { body mass index, } \\
\text { BSA: body } \\
\text { surface area. }\end{array}$ \\
\hline
\end{tabular}

Table 2. Echocardiographic characteristics

\begin{tabular}{|c|c|c|c|}
\hline Variable & Hypertension $n=226$ & Control $n=101$ & $\mathrm{p}$ \\
\hline LV MI $\left(\mathrm{g} / \mathrm{m}^{2}\right)$ & $96(27)$ & $73(15)$ & 0.001 \\
\hline RWT & $0.55(0.11)$ & $0.41(0.06)$ & 0.001 \\
\hline $\begin{array}{l}\text { LV geometry Normal } \\
\text { Conc remodeling Conc } \\
\text { hypertrophy }\end{array}$ & 28 (13) 98 (43) $100(44)$ & $68(67) 33(33) 0$ & 0.0010 .001 \\
\hline $\begin{array}{l}\text { LV volumes } \\
\text { end-diastolic }(\mathrm{mL}) \\
\text { end-systolic }(\mathrm{mL}) \mathrm{SV} \\
\text { index }\left(\mathrm{mL} / \mathrm{m}^{2}\right)\end{array}$ & $47(12) 17(6) 30(8)$ & $48(9.6) 18(5) 30(6)$ & 0.20 .80 .9 \\
\hline $\mathrm{LA}$ VI $\left(\mathrm{ml} / \mathrm{m}^{2}\right)$ & $38.7(12)$ & $29(7)$ & 0.02 \\
\hline LVEF (\%) & $63(6)$ & $63(6)$ & 0.76 \\
\hline $\mathrm{S}^{\prime}$ mitral $(\mathrm{cm} / \mathrm{s})$ & $8.1(2.2)$ & $9.9(2.2)$ & 0.03 \\
\hline GLS (\%) & $-18.8(2.5)$ & $-20.4(2)$ & 0.001 \\
\hline MAPSE (mm) & $13.8(2.8)$ & $15.5(2)$ & 0.001 \\
\hline $\begin{array}{l}\text { Diastolic function } \\
\text { Normal Grade } 1 \text { DD }\end{array}$ & 2117332 & 57440 & 0.0010 .001 \\
\hline $\begin{array}{l}\text { Grade } 2 \text { DD } \\
\mathbf{E} / \mathbf{e}^{\prime} \text { ratio }\end{array}$ & $9.5(3.7)$ & $6.6(2)$ & 0.001 \\
\hline PASP (mmHg) & $31(8.4)$ & $21(4)$ & 0.001 \\
\hline
\end{tabular}


Conc: concentric, DD: diastolic dysfunction, GLS: global longitudinal strain, LA: left atrium, LV: left ventricle, LVEF: left ventricle ejection fraction, MAPSE: mitral annulus plane systolic excursion, MI: mass index, PASP: pulmonary artery systolic pressure, RWT: relative wall thickness, VI: volume index
Conc: concentric, DD: diastolic dysfunction, GLS: global longitudinal strain, LA: left atrium, LV: left ventricle, LVEF: left ventricle ejection fraction, MAPSE: mitral annulus plane systolic excursion, MI: mass index, PASP: pulmonary artery systolic pressure, RWT: relative wall thickness, VI: volume index
Conc: concentric, DD: diastolic dysfunction, GLS: global longitudinal strain, LA: left atrium, LV: left ventricle, LVEF: left ventricle ejection fraction, MAPSE: mitral annulus plane systolic excursion, MI: mass index, PASP: pulmonary artery systolic pressure, RWT: relative wall thickness, VI: volume index
Conc: concentric, DD: diastolic dysfunction, GLS: global longitudinal strain, LA: left atrium, LV: left ventricle, LVEF: left ventricle ejection fraction, MAPSE: mitral annulus plane systolic excursion, MI: mass index, PASP: pulmonary artery systolic pressure, RWT: relative wall thickness, VI: volume index

Table 3. Echocardiographic characteristics in patients with hypertension according to ventricular geometry. $\mathrm{n}=\mathbf{2 2 6}$

\begin{tabular}{|c|c|c|c|c|}
\hline Variable & Normal $\mathrm{n}=28$ & $\begin{array}{l}\text { Concentric } \\
\text { remodeling } n=98\end{array}$ & $\begin{array}{l}\text { Concentric } \\
\text { hypertrophy } n= \\
100\end{array}$ & $\mathbf{p}$ \\
\hline $\begin{array}{l}\text { LV septum } \\
(\mathrm{mm})\end{array}$ & $9(0.9)$ & $11(1.2)$ & $13(1.4)$ & 0.001 \\
\hline RWT & $0.39(0.03)$ & $0.56(0.1)$ & $0.59(0.1)$ & 0.001 \\
\hline $\mathrm{LV} \mathrm{MI}\left(\mathrm{ml} / \mathrm{m}^{2}\right)$ & $77(19)$ & $78(12)$ & $119(21)$ & 0.001 \\
\hline $\begin{array}{l}\text { LV SVI } \\
\left(\mathrm{ml} / \mathrm{m}^{2}\right)\end{array}$ & $30(6.9)$ & $28(6.7)$ & $31(9)$ & 0.2 \\
\hline LA VI $\left(\mathrm{ml} / \mathrm{m}^{2}\right)$ & $34(19)$ & $35(9.6)$ & $43(14)$ & 0.001 \\
\hline $\begin{array}{l}\text { Diastolic } \\
\text { function Normal } \\
\text { Grade } 1 \text { DD } \\
\text { Grade } 2 \text { DD }\end{array}$ & 1117 & 6848 & 47323 & $\begin{array}{lll}0.001 & 0.001 & 0.001\end{array}$ \\
\hline PASP (mmHg) & $26.5(7)$ & $29(7.6)$ & $34(8.5)$ & 0.001 \\
\hline LVEF (\%) & $62(4.8)$ & $63.6(6)$ & $63(6.7)$ & 0.13 \\
\hline $\begin{array}{l}\mathrm{S}^{\prime} \text { mitral } \\
(\mathrm{cm} / \mathrm{s})\end{array}$ & $8.5(2.8)$ & $8.8(2.3)$ & $7.4(1.8)$ & 0.001 \\
\hline GLS (\%) & $-20.2(2)$ & $-19.6(2)$ & $-17.5(2.4)$ & 0.001 \\
\hline MAPSE (mm) & $15.8(2)$ & $14.9(2)$ & $12(2.7)$ & 0.001 \\
\hline
\end{tabular}




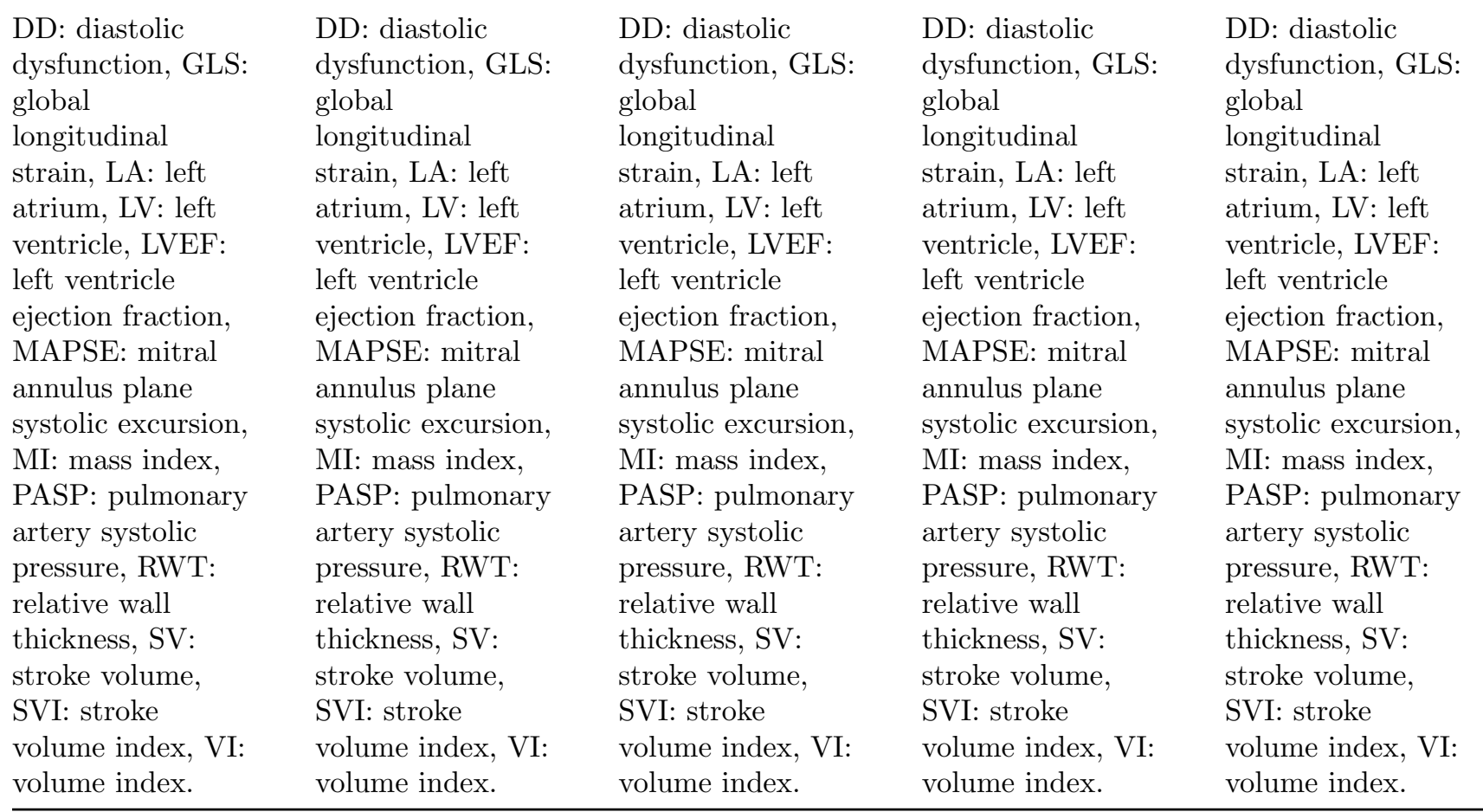

Figure 1. Boxplot showing the distribution of LVEF (left), MAPSE (center), and GLS (right) in patients with hypertension according to LV geometry. MAPSE and GLS panels show the decrease in longitudinal systolic function as the LV geometry worsens. Moreover, LVEF remains equal between groups.

Figure 2. ROC curve depicting low global longitudinal strain classification according to LV septum thickness. Low GLS was defined as $>-17 \%$.

Figure 3. ROC curve depicting low MAPSE classification according to LV septum thickness. Low MAPSE was defined according to sex and age.
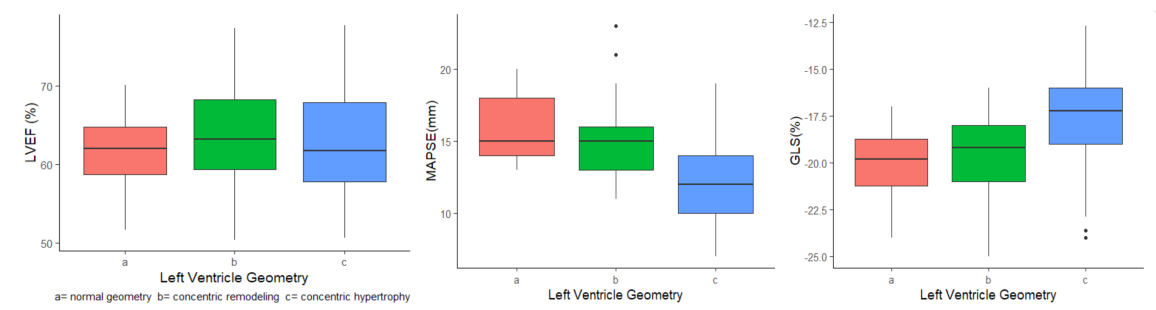

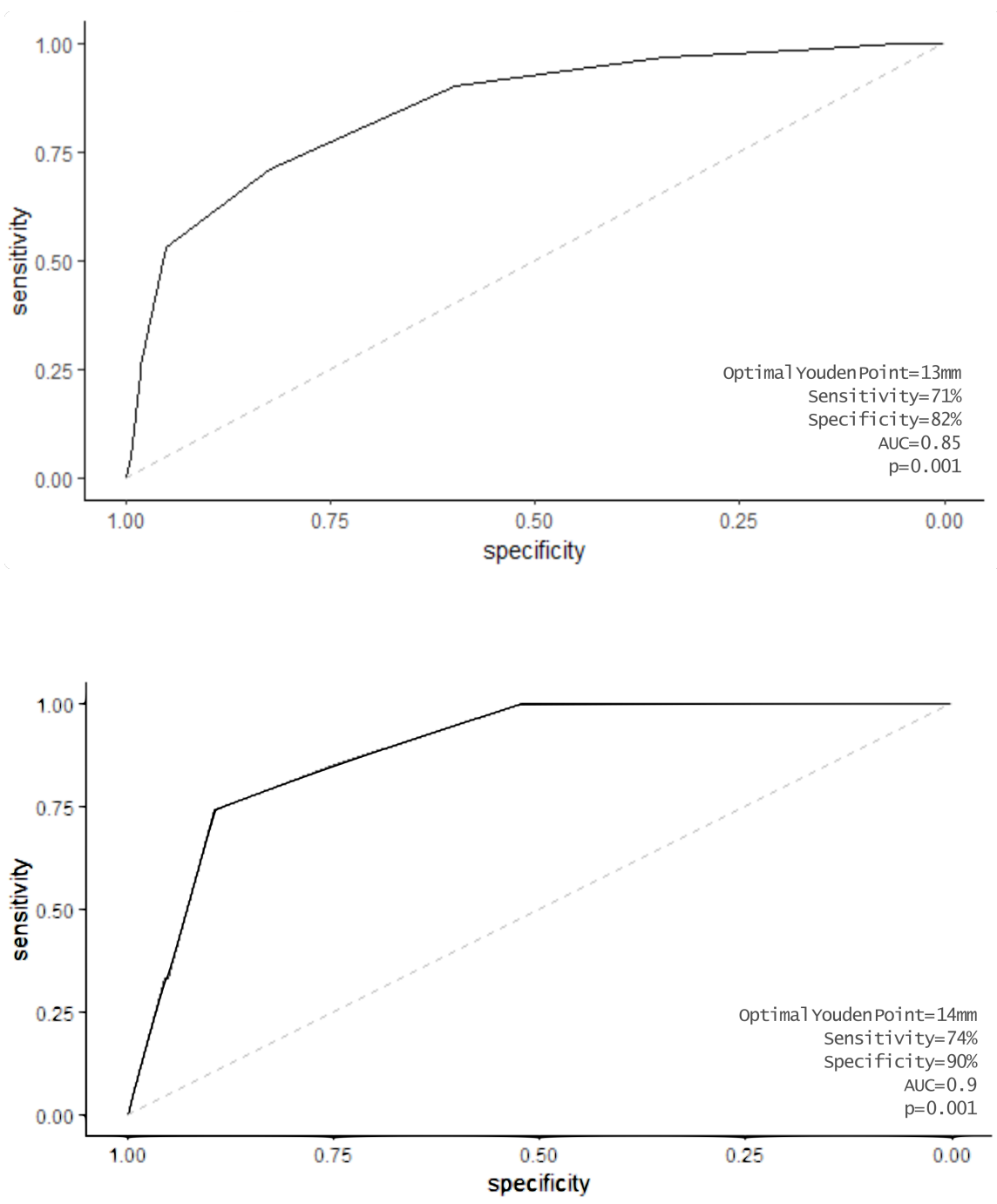